\title{
Energy Recycling from Sewage Sludge by Producing Solid Biofuel
} with Hydrothermal Carbonization

\author{
Peitao ZHAO ${ }^{1,2}$, Yafei SHEN ${ }^{2}$, Shifu GE ${ }^{1}$, Kunio YOSHIKAWA ${ }^{2}$ \\ ${ }^{1}$ Key Laboratory of Energy Thermal Conversion and Control of Ministry of Education, School of Energy \\ and Environment, Southeast University \\ NO.2 Sipailou, XuanWu District, Nanjing 210096, P.R. China \\ ${ }^{2}$ Department of Environmental Science and Technology, Tokyo Institute of Technology \\ G5-8 4259 Nagatsuta-cho, Midori-ku, Yokohama, Kanagawa 226-8503, Japan \\ E-mail address:pt.zhaoseu@gmail.com (ZHAO) yafeisjtu@ gmail.com (Shen) \\ TEL: +81-45-924-5586 FAX: +81-45-924-5586 \\ ge1962@126.com(GE) \\ TEL: +86-25-83792379 FAX: +86-25-5771-4489
}

Abstract: The hydrothermal (HT) conversion has been proposed to produce nitrogen, chlorine free solid biofuel or liquid fertilizer from high moisture and nitrogen content bio-wastes, such as municipal solid waste (MSW), mycelial waste, sewage sludge and paper sludge. However, the energy and economic efficiency of this process has not been fully investigated yet. This work focuses on energy recycling from sewage sludge by producing solid biofuel with HT carbonization, in order to optimize the operating parameters and evaluate the energy efficiency of this fuel production process. The effect of the HT temperature and holding time on the biofuel recovering ratio, calorific value and energy recovery rate was investigated. This evaluation fully considered the effect of the HT conditions, mechanical dewatering, thermal drying, and biofuel recovery ratio. Moreover, the energy consumption of sludge thermal drying was introduced to illustrate the economic efficiency of the HT biofuel production process more intuitively. The results show that the HT biofuel production process was more cost-effective than the conventional thermal drying. The HT temperature was the most important parameter to affect the biofuel properties. The carbon content of solid biofuel kept increasing both with HT temperature and holding time, resulting in an increase in the calorific value of biofuel; whereas, the biofuel recovering ratio $\alpha$, defined as the mass ratio of solid biofuel to raw sludge, also dropped causing a reduction in the energy recovery rate. After the HT temperature was above $200{ }^{\circ} \mathrm{C}$, the energy recovery rate was around $40 \%$. A moderate condition-HT temperature of $200{ }^{\circ} \mathrm{C}$ and holding time of 30 min was suggested to produce solid biofuel from 
sewage sludge with an energy recovery rate of $50 \%$. Practically, it is better to improve the intensity of mechanical dewatering to remove more water from the HT products in order to improve thermal efficiency.

Keywords: sewage sludge, hydrothermal carbonization, solid biofuel, biofuel recovery, energy efficiency

\section{Introduction}

Municipal wastewater treatment results in generating huge amount of sewage sludge, which requires proper and environmentally acceptable management before final disposal. The management of municipal sewage sludge (SS) is a difficult and expensive problem to solve for many countries. In China, about 20.76 million tons of SS with a water content of $80 \%$ has been produced in 2010 [1]. Moreover, this amount will be much huger at the end of 2015 according to the China's 12th Five-Year Construction Plan for National Urban Wastewater Treatment and Recycling Facilities [2], indicating that another sludge treatment facilities with a capacity of at least 5.18 million tons dried sludge has to be built to meet the environmental requirements in the following years. In a global context, it is organizationally, technically, and economically hardly possible to prevent or strongly reduce the amount of municipal wastewater because of the rapid urbanization, industrialization, and growth in population [3]. Besides that, the presence of toxic pollutants in municipal wastewater cannot be avoided because a large part of these toxics originates from diffuse sources. Accordingly, it is believed that the sludge output would remain increasing gradually in the coming decades [4], and its quality will not change significantly in the future. SS will therefore remain a permanent waste treatment problem requiring an appropriate solution [5].

Currently, bio-energy is an excellent energy recycling technology with bright prospect, giving its ability to recover energy from waste biomass $[1,6,7]$. The hydrothermal $(\mathrm{HT})$ conversion, which involves the application of heat and pressure to treat biomass in an aqueous medium, was verified as an effective way to densify the energy content of moist biomass without thermal drying [8]. For sludge, it aims to disintegrate the sludge and result in the formation and accumulation of dissolved products [9]. During the reaction, solid decomposition was significantly affected by reaction temperature rather than reaction time. Higher temperature resulted in higher solids conversion to solid biofuel [10].

The HT conversion has bright perspective with three main merits: 1) largely improving the dewaterability; 2) dramatically reduction in volume, especially for the municipal solid waste (MSW), sawdust, SS and leaves; 3) energy densification. Energy contents of the solid biofuel from primary SS carbonized at $140-200{ }^{\circ} \mathrm{C}$ for 4 hours ranged from 21.5 to $23.31 \mathrm{MJ} / \mathrm{kg}$, and kept increasing with carbonization [10]. Liu et al. [11] also stated that the energy densification was increased from 1.34 to 1.66 and 1.33 to 1.55 for coconut fiber and eucalyptus 
leaves, respectively. The highest energy yield was achieved at the lowest temperature adopted because of the relative high biofuel yield. Lu et al. [12] applied HT to produce powder-like solid biofuel from Japanese MSW, Indian MSW and Chinese MSW, at $220^{\circ} \mathrm{C}$ and $2.4 \mathrm{MPa}$ for $30 \mathrm{~min}$ with a lab-scale autoclave facility. It is reported that the volume based heating value (HV) of MSW was improved at around 6.4-9.0 times. Similar results were also obtained by deriving the data presented by Prawisudha et al., [13] indicating that this volume based energy density was improved around 4-5 times after the HT pretreatment in a pilot plant. The product was easily dryable to powdery fuel with a moisture content of $10 \%$ and an average dry basis (d.b.) $\mathrm{HV}$ of $20 \mathrm{MJ} / \mathrm{kg}$, as high as that of the low-grade sub-bituminous coal. Moreover, they also observed that the chlorine content of MSW could be reduced from 10,000 ppm (d.b.) to approximately 2,000 ppm (d.b.) resulting from the transformation to water-soluble inorganic chlorine. For the combustion characteristics, it was stated that the blending of HT pretreated MSW improved devolatization properties of coal and lowers the ignition temperature of coal $[12,14,15]$. He et al. [16] also state that the combustion of solid fuel produced from SS by HT is expected to be easier and more stable than raw sludge because of lower activation energy and pre-exponential factor. The solid fuel is supposed to be clean as about $60 \%$ of nitrogen and sulfur within SS can be removed during the HT conversion. Moisture content was found to affect the HT carbonization process; feedstocks with higher initial moisture content resulted in lower hydrochar yield [10].

Most of these works have focused on the feasibility of applying HT to produce solid biofuel [11, 13, 17-19], the kinetics and mechanism of HT solid fuel formation [10, 20], the biofuel' characterization [16, 21, 22], and the biofuels' combustion characteristics [7, 12, 14-16]. They have distinctly verified that the HT was an effective pretreatment process to produce clean solid biofuel from waste biomass by controlling the water content without prior drying. However, few of them focused on the energy and economic efficiency of this process by fully considering the HT operating conditions, dehydration performance, consequent thermal drying and biofuel recovery ratio, etc., which are very crucial for process optimization and commercialization of this technology. Therefore, this study mainly investigated on the mass and energy balance of solid biofuel production from SS by HT. The effect of HT temperature and holding time on the biofuel recovering ratio, calorific value of solid biofuel, water removal performance, and energy recovery rate were fully taken into account to evaluate the energy efficiency.

\section{Material and Methods}

\subsection{Experimental Procedures}

In this study, the dewatered activated sludge with a moisture content of $(85.94 \pm 0.22) \%$ was taken from a 
wastewater treatment plant in Japan . Its proximate and ultimate analysis results were shown in Table 1.

Fig.1 shows a diagram of the HT solid biofuel production process and an elementary diagram of the experimental facilities. During the HT treatment, the sludge pre-mixed with pure water (Wako Pure Chemical Industries, Ltd. Japan) as the mass ratio (wet basis, w.b.) of 2:1 (90 g sludge and $45 \mathrm{~g}$ pure water) was loaded into a glass tube with a volume of $500 \mathrm{~mL}$. Subsequently, the glass tube was put into the reactor, which was heated by an electronic heat jacket. After that, the reactor was sealed and the argon with a purity of $99.999 \%$ was supplied from a cylinder to the reactor in order to create an oxygen free circumstance. The reactor was then heated up to the target temperature and kept constant for a predetermined period. In this study, the HT temperature and holding time ranged from 180 to $240{ }^{\circ} \mathrm{C}$ and from 15 to 45 minutes, respectively. During the reaction, the mixer was kept stirring with its direction switching every 5 minutes to ensure the uniformity of reaction temperature in the samples. After finishing the reaction, the heater was turned off and the residual steam was discharged and cooled down with a water condenser. When the pressure and temperature fell down to the atmospheric and room temperature, the products were taken out from the glass tube and then kept in a bottle for further use. The condensed liquid was collected and mixed with the products from the glass tube. Each condition was repeated at least 3 times as the same procedure and the final products were mixed to reduce the experimental error.

Fig.1 Biofuel production process and an elementary diagram of experimental facilities

To calculate the recovery rate $\alpha$ of the solid fuel, about $60 \mathrm{~g}$ (dividing into three group) of the pre-mixed products was directly dried in an oven at $105^{\circ} \mathrm{C}$. And another $140 \mathrm{~g}$ was taken out to conduct the mechanical dewatering in order to evaluate the water removal efficiency of sludge. An elementary diagram of the dewatering device was also shown in Fig.1 (details about this device can be found in Zhao et al., [1]). Differing from the previous one [1], the dewatering pressure and time were $0.6 \mathrm{MPa}$ and 12 minutes respectively. During the dewatering process, the filter was collected by a beaker and its weight was measured by an electronic balance connecting to a computer. After that, the re-dewatered sludge was dried by a forced convective dryer, whose operating condition was air temperature of $30.4 \pm 0.4{ }^{\circ} \mathrm{C}$ and velocity of $1.34 \pm 0.04 \mathrm{~m} / \mathrm{s}$ all the time. During the drying process, the sample weight was continuously measured by an electronic balance ASP-4100 (AS-one, Japan) and was recorded in a computer with .XLS format at 6 minutes interval for further analysis. The drying process stopped after the sample weight was kept constant for $2 \mathrm{~h}$.

\subsection{Analytic Methods}



in $1 \mathrm{~kg}$ dry solid, was used to characterize the water removal ability. This value can be easily solved according to the weight loss of the sample.

Fig. 2 shows the boundary of the mass and energy balance in the current study. The solid recovering rate $\alpha$ was expressed as the ratio of the HT solid product to the raw sludge (d.b.). The proximate and ultimate analysis was used to characterize the solid biofuel property. The heat consumption in the HT was evaluated according to a batch-type HT equipment composing of a pressurized vessel, a boiler, a control unit, piping and incidental components. The vessel was made of SM400B low-carbon steel with a volume of around $1.5 \mathrm{~m}^{3}$. The heat capacity $C_{\text {bulk }}$ and the heat loss of the reactor have been theoretically and experimentally evaluated by Namioka et al [23]. Ignoring the weight loss and assuming the circumstance temperature is $25^{\circ} \mathrm{C}$, the energy input of the HT can be calculated as:

$m_{w} \cdot\left(H_{l, H T}-H_{l, 298}\right)+\left(m_{s} \cdot c_{p}+C_{b u l k}+3600 \times h_{b u l k} \cdot A \cdot \tau\right) \cdot\left(T_{H}-298\right)=X_{i n} \cdot\left(H_{g, H T}-H_{l, H T}\right)$

where $E_{H T, i n}$ is the energy input in the HT process; $m_{w}, m_{s}$ is the water and solid content in the sludge; $H$ is the enthalpy of the liquid, approximately equaling to that of water; $c_{p}$ is the specific heat capacity of sludge, 1.7 $\mathrm{kJ} /(\mathrm{kg} \cdot \mathrm{K})[17] ; \tau$ is the holding time, hour; $C_{b u l k}$ is the heat capacity of the reactor, $1550 \mathrm{~kJ} / \mathrm{K} ; h_{\text {bulk }}$ is the convective heat transfer coefficient; $A$ is the surface area of the reactor, $h_{\text {bulk }} \cdot A=0.032 \mathrm{~kW} / \mathrm{K}[23]$.

After HT, the steam in the reactor was released from saturated pressure to atmospheric pressure, following with a temperature decrease inside the reactor. Assuming that the temperature inside the reactor was $373 \mathrm{~K}$ when the pressure inside the reactor reached to atmospheric pressure, the amount of exhaust steam can be then calculated by Eq.3:

$$
\left(m_{w}+X_{i n}\right) \cdot\left(H_{l, H T}-H_{l, 373}\right)+m_{s} \cdot c_{p} \cdot\left(T_{H}-373\right)=X_{o u t} \cdot\left(H_{g, H T}-H_{l, 373}\right)
$$

The energy output $E_{H T, \text { out }}$ after HT can be estimate as:

$$
E_{H T, \text { out }}=X_{\text {out }} \cdot\left(H_{g, T H}-H_{l, 298}\right)
$$

The energy consumption of mechanical dewatering was derived from a $24 \mathrm{t} / \mathrm{d}$ pilot scale plant, which has been continually operated for 2 years. 
As for the thermal efficiency of dryer, the energy consumption in the commercial plants was about 1.2 $\mathrm{kg}($ steam $) / \mathrm{kg}$ (water) not including the cost of capital, labor, maintenance, and operating [24]. At a lab scale (capacity, $100 \mathrm{~kg} / \mathrm{h}$ ), it was around $70-75 \%$ for gas-agitated double screw type dryer [25] and about 25-62\% for screw conveyor dryer, a typical values obtained from the falling-rate drying period [26]. Fully taking all the above mentioned data into account, the thermal efficiency of the conventional drying process was assumed to be $70 \%$ in this study.

\section{Results and Discussion}

\subsection{Carbonization of sewage sludge}

Table 1 presents the proximate and ultimate analysis of the raw sludge and the HT products. The carbon content was increased from $51.2 \%$ to $68.0 \%$ and the corresponding HV was also improved from 4497 to 4821 $\mathrm{kcal} / \mathrm{kg}$. He et al. [16] also reported the higher heating values of SS was increased by at least $11 \%$ with the HT conversion. The $\mathrm{HV}$ of the solid fuel produced at $180^{\circ} \mathrm{C}$ and 15 minutes was lower than that of the raw sludge. This could be explained by that the volatile dissolution but not the SS carbonization played the most important role resulting in HV decrease. After lengthening the holding time, the SS carbonization became more and more important, the HV of the fuels were then improved by the HT conversion. The HV was increased with both the HT temperature and holding time. However, the energetic retention efficiency was decreased because of the reduction of biofuel yields, which were decreased both with increasing the HT temperature and holding time. Moreover, high HT temperature and long holding time means high energy consumption in HT conversion. Therefore, the process optimization should consider the energy efficiency of each separated process, including the HT conversion, mechanically dewatering, and thermal drying, in order to maximize the energy recovery rate.

Table 1 the ultimate and proximate analysis of the samples

Fig.3 illustrated the coalification band of the upgraded SS. This coalification was mainly attributed to the hydrolysis reaction resulting from the heat, pressure, and time [19]. The quality of solid biofuels produced by the HT could be compared to the lignite or even sub-bituminous, depending on the reaction severity. Mass balance analyses indicated that the feedstock carbonization retained a significant fraction of carbon in the solid parts [27]. Both the atomic ratio of $\mathrm{H} / \mathrm{C}$ and $\mathrm{O} / \mathrm{C}$ kept decreasing with the $\mathrm{HT}$ temperature; yet, the degree was relevant to both the HT conditions and the feedstock. All the HT products exhibited lower H/C and O/C ratios than the initial materials, owing to the evolution of $\mathrm{H}_{2} \mathrm{O}$ and $\mathrm{CO}_{2}$ due to the dehydration and decarboxylation reactions [28]. Dehydration is generally explained by elimination of hydroxyl groups, while decarboxylation is 
the thermal cracking of the long chain carboxylic acids. Chemical dehydration significantly carbonizes biomass by lowering the $\mathrm{H} / \mathrm{C}$ and $\mathrm{O} / \mathrm{C}$ ratios [20]. According to the composition of the hydrochar produced from municipal wastes, Berge et al. [27] concluded that both the dehydration and decarboxylation occurred during carbonization, resulting in structures with high aromaticity. Longer HT holding time seemed to decrease oxygen containing functional groups while carbon aromaticity structure increased, thereby rendering hydrochars highly hydrophobic [16]. The evolution of the $\mathrm{H} / \mathrm{C}$ and $\mathrm{O} / \mathrm{C}$ atomic ratios follows essentially the path of a dehydration process, similar to that previously observed for the HT transformation of saccharides such as glucose, sucrose or starch [22]. Significant decarboxylation only appeared after plenty of water has been generated [20]. The dehydroxylation and condensation reaction are regarded as possible paths for water sources. Above $150{ }^{\circ} \mathrm{C}$, the carboxyl and carbonyl groups were rapidly degraded to release $\mathrm{CO}_{2}$ and $\mathrm{CO}$ respectively. Early observations concluded that the HT decomposition of the formic acid, which is formed in significant amounts during the cellulose degradation, yielding primarily $\mathrm{CO}_{2}$ and $\mathrm{H}_{2} \mathrm{O}$, was also one likely source for $\mathrm{CO}_{2}$ formation [29].

Fig.3 The coalification band of sewage sludge with HT treatment

Many reaction mechanisms would contribute to the coalification in HT conversion, whereas more detailed reaction pathways and kinetics are largely unknown except for the HT degradation of glucose. According to previous studies on hydrochar formation mechanisms [16, 18, 21, 30-35], the hydrocarbon can be obtained via three main reaction pathways: (1) direct solid-solid conversion of biomass materials (termed “char") undergoing devolatilization, condensation, dehydration and decarboxylation; (2) polymerization of dissolved intermediates degraded from the original biomass towards polyfurans; (3) carbonization via further intermolecular.

\subsection{Mass balance of HT solid biofuel production}

Fig.4 shows a typical mass balance of the HT solid biofuel production process run under a temperature of $200{ }^{\circ} \mathrm{C}$ and holding time of $30 \mathrm{~min}$. The initial ratio of sludge to water was 2:1 with about $90.3 \mathrm{~g} \mathrm{SS}$ and $45.2 \mathrm{~g}$ water in the parent materials. Accordingly, the solid content of the parent materials was $9.4 \%$, about $12.7 \mathrm{~g}$. After the HT, about $132.4 \mathrm{~g}$ (97.8\% of the initial weight) product was obtained and the other $3.0 \mathrm{~g}$ was lost resulting from the possible weight loss and uncondensed gases. Following with a mechanically dewatering, most of the liquid (about $104.6 \mathrm{~g}$, accounting for $77.2 \%$ ) within the HT product was removed and $27.8 \mathrm{~g}$ dewatered residues (occupying 20.5\%) was obtained. If not accounting the water added in the HT stage, about $60 \mathrm{~g}$ water (4.7 $\mathrm{kg}$ water $/ \mathrm{kg}$ solid) was removed by the combination of HT treatment and mechanical dewatering. It indicates the HT treatment was an effective solution to improve sludge dewaterability. After the thermal drying, 
about $11.58 \mathrm{~g}$ HT solid biofuel was acquired, representing $8.6 \%$ of the total sample weight. The biofuel recovery rate $\alpha$ was solved as $91.3 \%$ at this operating condition. Due to the avoidance of the forced evaporation of water, the energy consumption in HT was expected to be largely reduced comparing with the traditional SS thermal drying.

Fig.4 Evaluation of biofuel recovery from sludge by employing HT in Lab-scale

Table 2 listed a mass balance analysis of all the operating conditions mentioned in this study. It indicated that the weight loss of all these samples was lower than 3.5\%. The sludge dewatering performance kept improving both with the HT temperature and holding time as indicated by the decrease in "dewatered residuals". For the sample treated under $240{ }^{\circ} \mathrm{C}$, the amount of "dewatered residuals" did not always decrease with the holding time. One possible reason was the sludge particles were too fine. Although the hydrophobic was improved [16], no effective porosity was formed during the mechanical dewatering, resulting in an increase in the resistance to filtration [36]. The other one was the O-ring placed in the connection increased the resistance to filtration and reduced the pressure acting on the sample surface due to the small volume of sample.

In virtue of the improvement of dewaterability, the amount of "evaporated liquid" was largely reduced for HT pretreated sample. The energy density of the SS was enhanced by the HT with the exception of the sample treated at $180{ }^{\circ} \mathrm{C}$ and $15 \mathrm{~min}$. Its reason has been discussed in section 3.1. The energy density was improved continuously; whereas the fuel recovery ratio kept decreasing both with increasing the HT temperature and holding time. This result implies that there existed an optimal operating condition to maximize the energy output of HT solid biofuel production process. Moreover, the energy density and corresponding fuel recovery ratio must be taken into account when evaluating the economic efficiency.

All these data show that most of the liquid could be removed by combining the HT pretreatment with mechanical dewatering prior to thermal drying. After the HT pretreatment and dewatering, the wet basis HV of the products was largely improved to achieve the self-sustaining combustion.

Table 2 Evaluation of mass balance of solid biofuel production by HT

\subsection{Energy balance}

Fig.5 illustrates an energy balance of the proposed process (capacity $1 \mathrm{t} / \mathrm{batch}$ ) producing solid biofuel under a temperature of $200{ }^{\circ} \mathrm{C}$ and holding time of 30 mins. It clearly shows that the HT pretreatment could be used to produce solid biofuel to recover energy from the high moist SS. Under the current condition, about $47.6 \%$ of the energy generated from the solid biofuel combustion could be recovered in the form of heat or power; the other 
$52.4 \%$ could be utilized to run the fuel production process, including the HT treatment, mechanical dewatering (press filter) and thermal drying (forced evaporation). Moreover, it is noteworthy to mention that this calculation assumed that the water residing in the solid after mechanical dewatering was removed by forced evaporation and the reactor was preheated every time. However, the reactor was required pretreating only once in a sequence operating process. Besides, the residing water was typically removed to around $20 \%$ by natural drying, which has been demonstrated to be improved by the HT pretreatment [37-39]. Therefore, the energy consumption could be reduced in practical so that more energy could be recycled. As indicated in Table 3, about $59.6 \%$ of the energy generated from the biofuel combustion could be recycled when ignoring the reactor preheating process.

Fig.5 Energy balance of solid biofuel production by HT pretreatment

In order to illustrate the energy efficiency more intuitively, Fig.5 also compares the energy consumption of the conventional thermal drying with that of the HT biofuel production process. Obviously, the heat generated from combustion of the dried SS could not fulfill the energy demand for water evaporation in conventional drying. Additional fuel with energy of 5.3 MJ should be added in order to treat 1 ton sludge with a moisture content of $85.94 \%$. However, in HT process, the water within sludge was removed mainly by mechanical dewatering, not forced evaporation. Only the sensitive heat was required to improve the temperature of SS and water under a certain pressure. About $47.6 \%$ of the heat generated from the biofuel combustion could be recovered. This result indicates that the biofuel production from the high moist SS by employing the HT treatment was not only feasible in the view of technique, but also cost effective in terms of energy efficiency. In a similar process employing the steam explosion to produce solid biofuel from SS and leaves, Zhao et al. [1] reported that the energy consumption of the thermal pretreatment was only about $22 \%$ of that of consumed in the conventional thermal drying, which was consistent with that reported by Namioka et al [17].

Table 3 shows the energy consumption and recovery under various operating conditions. After the HT temperature was above $200{ }^{\circ} \mathrm{C}$, the energy recovery rate was around $40 \%$. If not taking the reactor preheating into account, the energy recovery rate was close to $60 \%$. Before the temperature reaching $240{ }^{\circ} \mathrm{C}$, it kept increasing with the HT temperature and holding time. The thermal drying process is the most energy-intensive one during the biofuel production, accounting for about $70 \%$ of the total energy consumption. Thus, one of the efficient ways to save energy was to improve the intensity of mechanical dewatering to remove more water from HT products. The other one is to lengthen the dewatering time. Practically, the pressure for press filter and time were about 1.2 $\mathrm{MPa}$ and 2 hours, respectively. In this case, the moisture content of the products could be reduced to about $40 \%$ for SS [17, 37], much lower than that reported in Table 2 . Thus, the energy consumption 
could be further reduced in practical. Considering the energy consumption of HT treatment, about half of the energy was consumed in the reactor preheating. Therefore, it would be better to shorten the interval between two batches to save energy.

\section{Table 3 Evaluation of energy recovery from solid biofuel production by HT}

\section{Conclusions}

This work focused on the mass and energy balance of solid biofuel production from SS by hydrothermal (HT) carbonization in order to optimize the operating parameters. The results show that the HT temperature was the most important parameter to affect the biofuel property. The sludge dewaterability, the carbon content and heating value of the biofuel were improved with increase of the HT temperature and hold time; whereas the ratio of the solid biofuel to raw sludge (biofuel recovering rate, $\alpha$ ) drops causing a reduction in the energy recovery ratio. Thus, the process optimization should fully take into account the dehydration performance, drying performance, biofuel recovering rate $\alpha$ and calorific value to improve the thermal efficiency and lower the cost of biofuel production. According to the energy balance, the energy recovery rate was around $40 \%$ after the HT temperature was over $200{ }^{\circ} \mathrm{C}$. To save energy, a moderate condition-HT temperature of $200{ }^{\circ} \mathrm{C}$ and holding time of 30 min was suggested to produce solid biofuel from SS with an energy recovery rate of $50 \%$.

\section{Acknowledgement}

This work was financially supported by the State Scholarship Fund of China under Grant No.2011609050, No. 201206230168, and National Science and Technology Major Project of China (Water Program) (2010ZX07319002). This research work was also supported by Strategic China-Japan Cooperative Program on "Science and Technology (S\&T) for Environmental Conservation and Construction of a Society with Less Environmental Burden" of the National Nature Science Foundation of China and Japan Science and Technology Agency (No. 21161140329).

\section{References}

[1] P. Zhao, S. Ge, K. Yoshikawa. An orthogonal experimental study on Solid fuel production from sewage sludge by employing steam explosion. Appl Energy. 112 (2013) 1213-21.

[2] General Office of the State Council of the People's Republic of China. The China's 12th Five-Year Construction Plan for National Urban Wastewater Treatment and Recycling Facilities. April 5th, 2012.

[3] W. Rulkens. Sewage sludge as a biomass resource for the production of energy: Overview and assessment of 
the various optionsł. Energ Fuel. 22 (2007) 9-15.

290

291

292

293

294

295

296

297

298

299

300

301

302

303

304

305

306

307

308

309

310

311

312

313

314

[4] Y. Cao, A. Pawłowski. Sewage sludge-to-energy approaches based on anaerobic digestion and pyrolysis: Brief overview and energy efficiency assessment. Renew Sust Energ Rev. 16 (2012) 1657-65.

[5] Ronald J. Leblanc, Peter Matthews, R.P. Richard. Global atlas of excreta, wastewater sludge, and biosolids management: Moving forward the sustainable and welcome uses of a global resource. UN-HABITAT2009.

[6] A. Demirbaş. Biomass resource facilities and biomass conversion processing for fuels and chemicals. Energ Convers Manage. 42 (2001) 1357-78.

[7] A. Demirbas. Biofuels sources, biofuel policy, biofuel economy and global biofuel projections. Energ Convers Manage. 49 (2008) 2106-16.

[8] Y. Yu, J. Liu, R. Wang, J. Zhou, K. Cen. Effect of hydrothermal dewatering on the slurryability of brown coals. Energ Convers Manage. 57 (2012) 8-12.

[9] E. Neyens, J. Baeyens. A review of thermal sludge pre-treatment processes to improve dewaterability. J Hazard Mater. 98 (2003) 51-67.

[10] E. Danso-Boateng, R. Holdich, G. Shama, A. Wheatley, M. Sohail, S. Martin. Kinetics of faecal biomass hydrothermal carbonisation for hydrochar production. Appl Energy. 111 (2013) 351-7.

[11] Z. Liu, A. Quek, S.K. Hoekman, R. Balasubramanian. Production of solid biochar fuel from waste biomass by hydrothermal carbonization. Fuel. 103 (2013) 943-9.

[12] L. Lu, T. Namioka, K. Yoshikawa. Effects of hydrothermal treatment on characteristics and combustion behaviors of municipal solid wastes. Appl Energy. 88 (2011) 3659-64.

[13] P. Prawisudha, T. Namioka, K. Yoshikawa. Coal alternative fuel production from municipal solid wastes employing hydrothermal treatment. Appl Energy. 90 (2012) 298-304.

[14] M. Muthuraman, T. Namioka, K. Yoshikawa. Characteristics of co-combustion and kinetic study on hydrothermally treated municipal solid waste with different rank coals: A thermogravimetric analysis. Appl Energy. 87 (2010) 141-8.

[15] M. Muthuraman, T. Namioka, K. Yoshikawa. A comparison of co-combustion characteristics of coal with wood and hydrothermally treated municipal solid waste. Bioresour Technol. 101 (2010) 2477-82.

[16] C. He, A. Giannis, J.-Y. Wang. Conversion of sewage sludge to clean solid fuel using hydrothermal carbonization: Hydrochar fuel characteristics and combustion behavior. Appl Energy. 111 (2013) 257-66.

[17] T. Namioka, Y. Morohashi, R. Yamane, K. Yoshikawa. Hydrothermal treatment of dewatered sewage sludge cake for solid fuel production. J Environ Eng. 4 (2009) 68-77. 

hydrothermal biomass gasification. Chem Eng Technol. 31 (2008) 1561-8.

[19] M. Nonaka, T. Hirajima, K. Sasaki. Upgrading of low rank coal and woody biomass mixture by hydrothermal treatment. Fuel. 90 (2011) 2578-84.

[20] A. Funke, F. Ziegler. Hydrothermal carbonization of biomass: a summary and discussion of chemical mechanisms for process engineering. Biofuel Bioprod Bior. 4 (2010) 160-77. [21] S. Kang, X. Li, J. Fan, J. Chang. Characterization of Hydrochars Produced by Hydrothermal Carbonization of Lignin, Cellulose, d-Xylose, and Wood Meal. Ind Eng Chem Res. 51 (2012) 9023-31. hydrothermal carbonization of saccharides. Chem-eur J. 15 (2009) 4195-203.

[23] T. Namioka, M. Miyazaki, Y. Morohashi, K. Umeki, Y. Kunio. Modeling and analysis of batch-type thermal sludge pretreatment for optimal design. J Environ Eng. 3 (2008) 170-81. [24] J. Werther. Potentials of biomass co-combustion in coal-fired boilers. Proceedings of the 20th International Conference on Fluidized Bed Combustion. Springer, Xi'an, China, 2010. pp. 27-42. [25] H.S. Kim, M.S. Shin, D.S. Jang, E.S. Na. A study for the thermal treatment of dehydrated sewage sludge with gas-agitated double screw type dryer. J Environ Sci Heal A. 40 (2005) 203-13. [26] S. Waje, B. Thorat, A. Mujumdar. An experimental study of the thermal performance of a screw conveyor dryer. Dry Technol. 24 (2006) 293-301. waste streams. Environ Sci Technol. 45 (2011) 5696-703.

[28] J. Akhtar, N.A.S. Amin. A review on process conditions for optimum bio-oil yield in hydrothermal liquefaction of biomass. Renew Sust Energ Rev. 15 (2011) 1615-24. (1998) 2-10.

[30] A. Kruse, P. Maniam, F. Spieler. Influence of proteins on the hydrothermal gasification and liquefaction of biomass. 2. Model compounds. Ind Eng Chem Res. 46 (2007) 87-96.

[31] E. Dinjus, A. Kruse, N. Tröger. Hydrothermal carbonization-1. Influence of lignin in lignocelluloses. Chem Eng Technol. 34 (2011) 2037-43.

347 [32] C. Falco, N. Baccile, M.-M. Titirici. Morphological and structural differences between glucose, cellulose and lignocellulosic biomass derived hydrothermal carbons. Green Chem. 13 (2011) 3273-81. 
349 [33] M. Zhang, H. Yang, Y. Liu, X. Sun, D. Zhang, D. Xue. Hydrophobic precipitation of carbonaceous spheres 350 from fructose by a hydrothermal process. Carbon. 50 (2012) 2155-61.

351 [34] B. Hu, K. Wang, L. Wu, S.H. Yu, M. Antonietti, M.M. Titirici. Engineering carbon materials from the 352 hydrothermal carbonization process of biomass. Adv Mater. 22 (2010) 813-28.

353 [35] A. Kruse, A. Funke, M.-M. Titirici. Hydrothermal conversion of biomass to fuels and energetic materials. 354 Curr Opin Chem Biol. (2013).

355 [36] P. Zhao, S. Ge, Z. Chen, X. Li. Study on Pore Characteristics of Flocs and Sludge Dewaterability Based on 356 Fractal Methods (Pore Characteristics of Flocs and Sludge Dewatering). Appl Therm Eng. 58 (2013) $217-23$.

357 [37] Z.L. Jiang, D.W. Meng, H.Y. Mu, K. Yoshikawa. Study on the hydrothermal drying technology of sewage 358 sludge. Sci China Technol Sci. 53 (2010) 160-3.

359 [38] D. Meng, Z. Jiang, K. Yoshikawa, H. Mu. The effect of operation parameters on the hydrothermal drying 360 treatment. Renew Energ. 42 (2012) 90-4.

361 [39] P. Zhao, S. Ge, C. Areeprasert, D. Ma, K. Yoshikawa. Effect of the hydrothermal pretreatment on the 362 convective drying of paper sludge. Sci China Technol Sci. (2013) submitted to SCIENCE CHINA 363 Technological Sciences. 


\section{Figures' Captions}

Fig.1 Fuel production process and an elementary diagram of experimental facilities

Fig.2 Boundary of mass and energy balance calculation in current study

Fig.3 The coalification band of sewage sludge with HT treatment

Fig.4 Evaluation of fuel recovery from sludge by employing HT in Lab-scale

Fig.5 Energy balance of solid fuel production by HT pretreatment

Note: all figures are color on the Web (free of charge) and in black-and-white in print

\section{Tables' Captions}

Table 1 the ultimate and proximate analysis of the samples

Table 2 Evaluation of mass balance of solid fuel production by HT

Table 3 Evaluation of energy recovery from solid fuel production by HT 
Table 1 the ultimate and proximate analysis of the samples

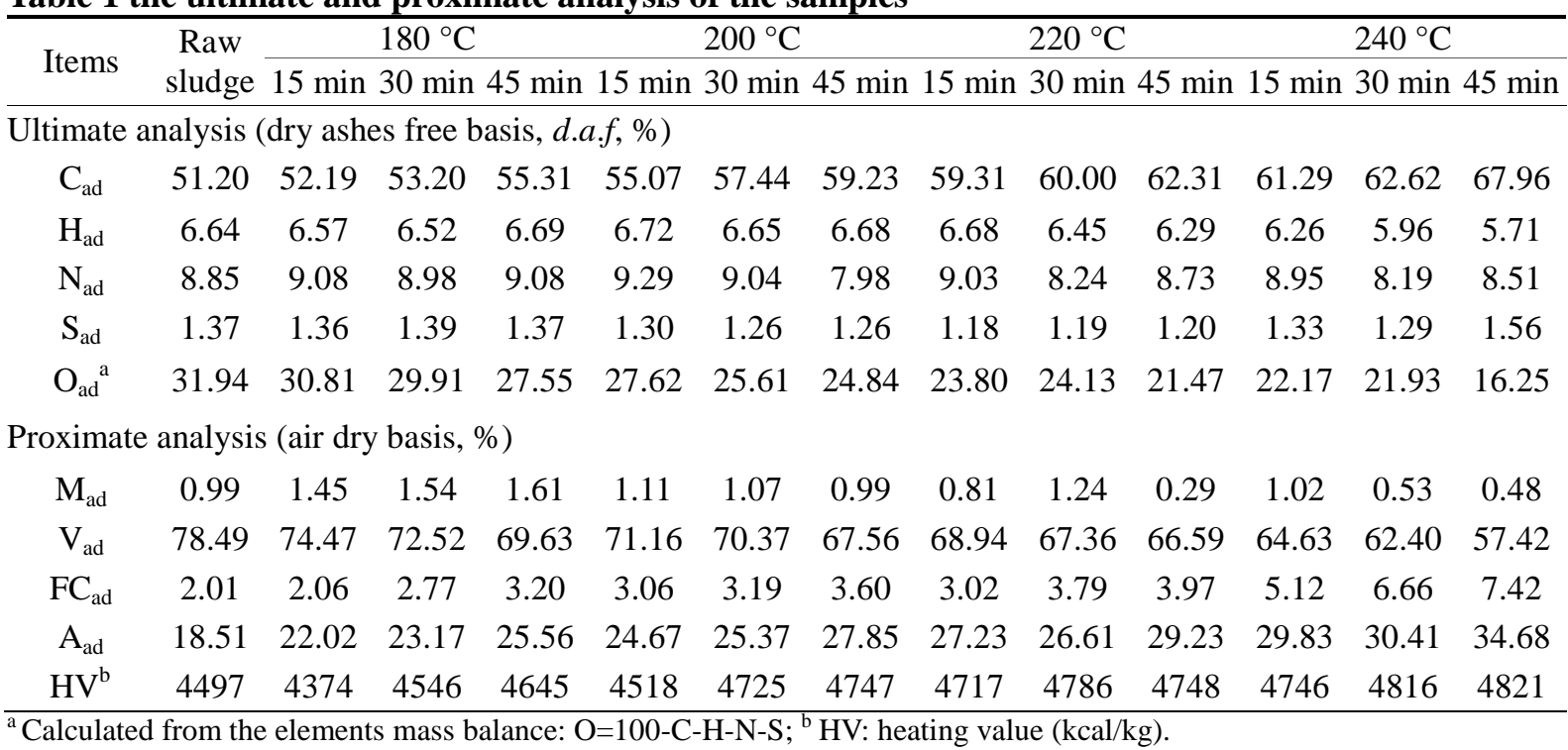


Table 2 Evaluation of mass balance of solid fuel production by HT

\begin{tabular}{|c|c|c|c|c|c|c|c|c|c|}
\hline \multirow[b]{2}{*}{ samples } & \multirow[b]{2}{*}{$\begin{array}{l}\text { Input } \\
(\%)\end{array}$} & \multicolumn{2}{|c|}{ Hydrothermal (\%) } & \multicolumn{2}{|c|}{ Dewatering $(\%)$} & \multicolumn{2}{|c|}{ Thermal drying (\%) } & \multirow[b]{2}{*}{$\begin{array}{c}\mathrm{HV} \\
(\mathrm{kcal} / \mathrm{kg})\end{array}$} & \multirow[b]{2}{*}{$\alpha(\%)$} \\
\hline & & Gas+loss & $\begin{array}{c}\text { HT } \\
\text { products }\end{array}$ & $\begin{array}{c}\text { Separated } \\
\text { liquid }\end{array}$ & $\begin{array}{c}\text { Dewatered } \\
\text { residuals }\end{array}$ & $\begin{array}{c}\text { Evaporated } \\
\text { liquid }\end{array}$ & Solid fuel & & \\
\hline Raw sludge & 100 & - & - & 29.70 & 70.30 & 56.24 & 14.06 & 4497 & 100 \\
\hline $15 \mathrm{~min}$ & 100 & 1.36 & 98.64 & 68.08 & 30.56 & 21.48 & 9.09 & 4374 & 96.94 \\
\hline $30 \mathrm{~min}$ & 100 & 1.89 & 98.11 & 72.89 & 25.23 & 16.45 & 8.77 & 4546 & 93.91 \\
\hline $45 \mathrm{~min}$ & 100 & 1.92 & 98.08 & 77.35 & 20.74 & 12.26 & 8.48 & 4645 & 90.59 \\
\hline $15 \mathrm{~min}$ & 100 & 3.06 & 96.94 & 74.23 & 22.72 & 14.00 & 8.72 & 4518 & 93.26 \\
\hline $30 \mathrm{~min}$ & 100 & 2.22 & 97.78 & 77.24 & 20.54 & 11.99 & 8.55 & 4725 & 91.27 \\
\hline $45 \min$ & 100 & 1.29 & 98.71 & 80.11 & 18.60 & 10.31 & 8.29 & 4747 & 88.40 \\
\hline $15 \mathrm{~min}$ & 100 & 2.42 & 97.58 & 76.68 & 20.89 & 12.38 & 8.52 & 4717 & 90.75 \\
\hline${ }^{220} 30 \mathrm{~min}$ & 100 & 3.47 & 96.53 & 77.81 & 18.72 & 10.60 & 8.11 & 4786 & 86.60 \\
\hline $45 \min$ & 100 & 2.65 & 97.35 & 81.03 & 16.32 & 8.41 & 7.91 & 4748 & 84.43 \\
\hline $15 \mathrm{~min}$ & 100 & 2.12 & 97.88 & 80.73 & 17.15 & 9.18 & 7.97 & 4746 & 85.16 \\
\hline $24030 \mathrm{~min}$ & 100 & 1.98 & 98.02 & 79.40 & 18.62 & 10.94 & 7.68 & 4816 & 82.07 \\
\hline $45 \mathrm{~min}$ & 100 & 3.24 & 96.76 & 78.51 & 18.25 & 10.93 & 7.33 & 4821 & 78.14 \\
\hline
\end{tabular}


Table 3 Evaluation of energy recovery from solid fuel production by HT

\begin{tabular}{|c|c|c|c|c|c|c|c|c|c|}
\hline Samples & $\begin{array}{l}\text { Input in } \\
\mathrm{HT}^{\mathrm{a}}(\mathrm{MJ})\end{array}$ & $\begin{array}{l}\text { Input in } \\
\text { HT (MJ) }\end{array}$ & $\begin{array}{c}\text { Dewatering } \\
(\mathrm{MJ})\end{array}$ & $\begin{array}{c}\text { Thermal } \\
\text { drying(MJ) }\end{array}$ & $\begin{array}{l}{ }^{\mathrm{a}} \text { Total input } \\
\left(\times 10^{3} \mathrm{MJ}\right)\end{array}$ & $\begin{array}{l}\text { Total input } \\
\left(\times 10^{3} \mathrm{MJ}\right)\end{array}$ & $\begin{array}{l}\text { Total output } \\
\left(\times 10^{3} \mathrm{MJ}\right)\end{array}$ & $\beta^{\mathrm{a}}(\%)$ & $\beta(\%)$ \\
\hline Raw sludge & 0 & 0 & 0 & 3181.93 & 3.18 & - & 2655.57 & -19.82 & - \\
\hline $15 \mathrm{~min}$ & 603.73 & 331.47 & 6.43 & 1208.00 & 1.82 & 1.55 & 2503.90 & 27.39 & 38.26 \\
\hline${ }^{180} 30 \mathrm{~min}$ & 608.79 & 336.52 & 6.43 & 933.41 & 1.57 & 1.28 & 2574.71 & 38.57 & 49.37 \\
\hline $45 \mathrm{~min}$ & 613.85 & 341.58 & 6.43 & 699.43 & 1.34 & 1.05 & 2539.71 & 46.89 & 57.85 \\
\hline $15 \mathrm{~min}$ & 639.04 & 331.88 & 6.43 & 797.07 & 1.46 & 1.14 & 2541.51 & 42.02 & 54.37 \\
\hline $20030 \mathrm{~min}$ & 644.75 & 337.58 & 6.43 & 683.92 & 1.35 & 1.03 & 2602.43 & 47.57 & 59.64 \\
\hline C $45 \mathrm{~min}$ & 650.46 & 343.29 & 6.43 & 590.81 & 1.26 & 0.94 & 2534.09 & 49.65 & 62.05 \\
\hline $15 \mathrm{~min}$ & 674.51 & 332.39 & 6.43 & 704.32 & 1.40 & 1.04 & 2583.54 & 45.20 & 58.73 \\
\hline${ }^{220} 30 \mathrm{~min}$ & 680.87 & 338.74 & 6.43 & 606.56 & 1.32 & 0.95 & 2560.56 & 47.14 & 61.11 \\
\hline C $45 \mathrm{~min}$ & 687.23 & 345.10 & 6.43 & 485.31 & 1.20 & 0.84 & 2479.39 & 50.20 & 64.65 \\
\hline $15 \mathrm{~min}$ & 710.20 & 333.01 & 6.43 & 528.37 & 1.28 & 0.87 & 2526.83 & 47.84 & 63.64 \\
\hline$\stackrel{240}{{ }^{2} \mathrm{C}} 30 \mathrm{~min}$ & 717.21 & 340.02 & 6.43 & 624.35 & 1.39 & 0.97 & 2504.66 & 42.25 & 58.41 \\
\hline C $45 \mathrm{~min}$ & 724.21 & 347.03 & 6.43 & 621.74 & 1.40 & 0.98 & 2395.38 & 39.21 & 56.16 \\
\hline
\end{tabular}

a: based on the assumption that the reactor was preheated every time. 


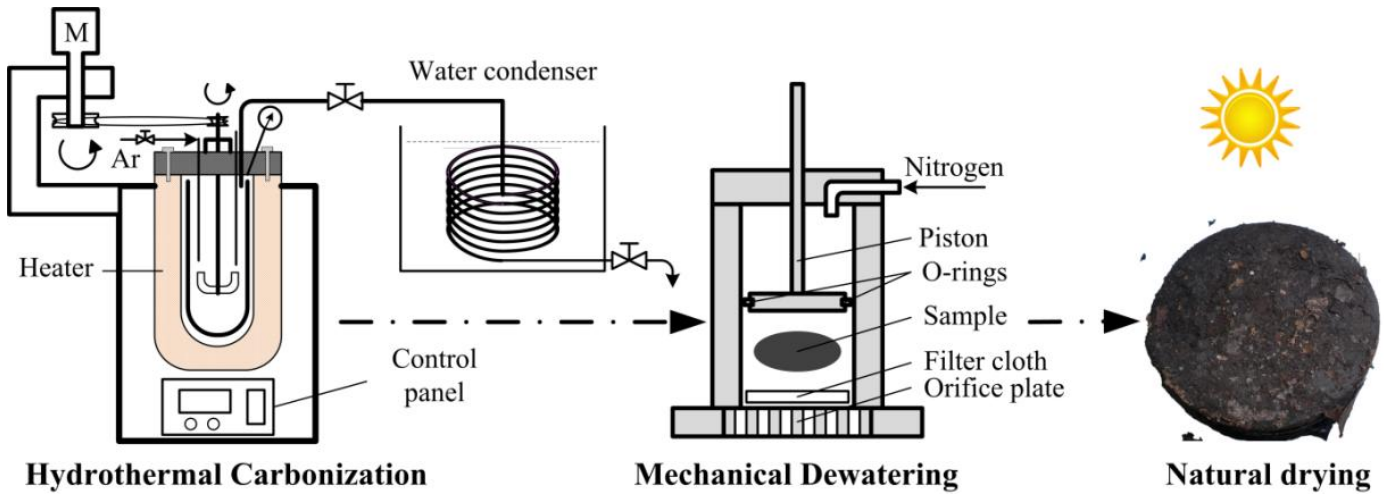

Fig.1 (color on the Web (free of charge) and in black-and-white in print) 


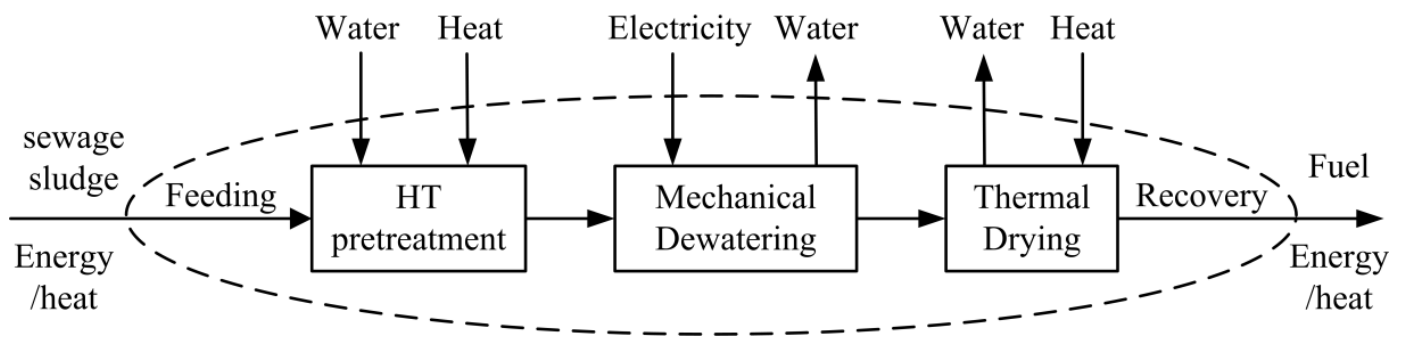

Fig. 2 


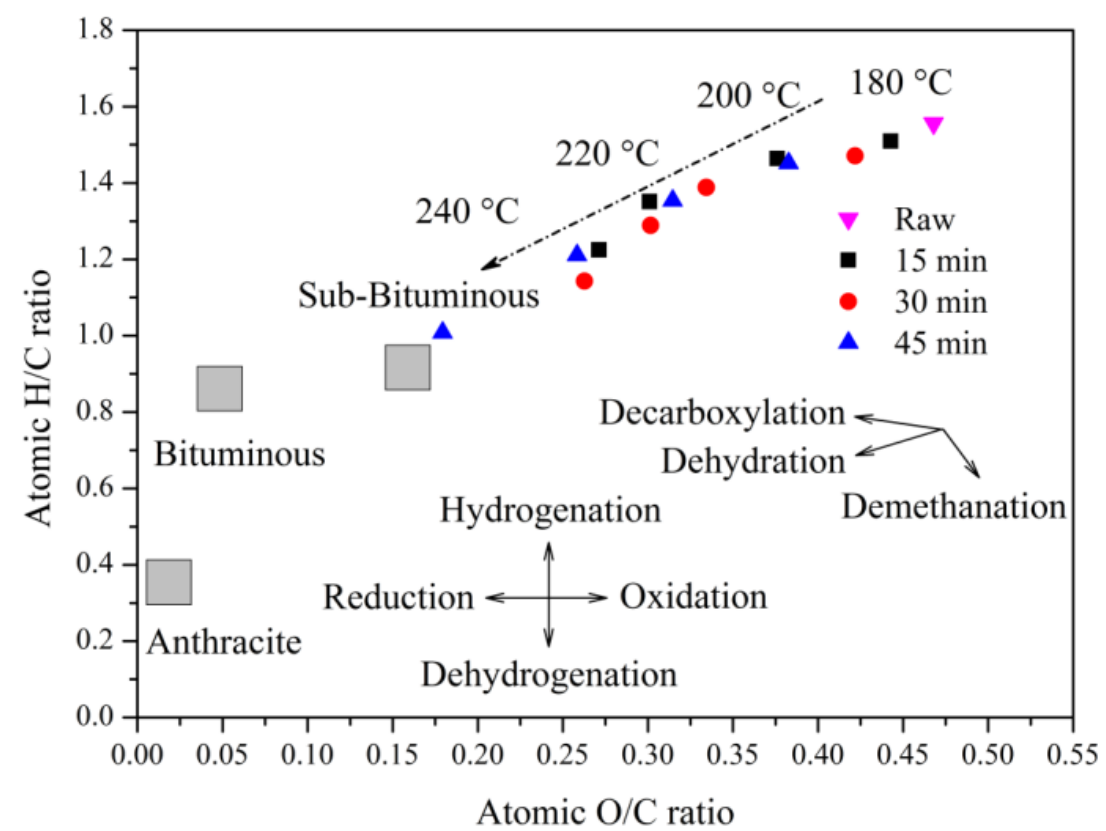

Fig.3 (color on the Web (free of charge) and in black-and-white in print) 


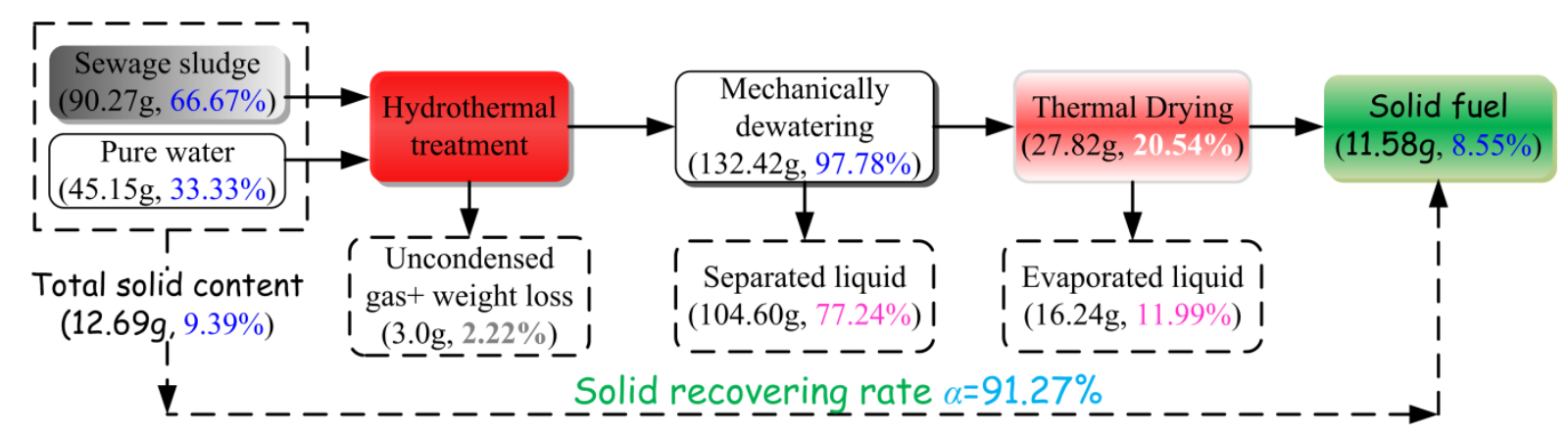

Fig.4 (color on the Web (free of charge) and in black-and-white in print) 


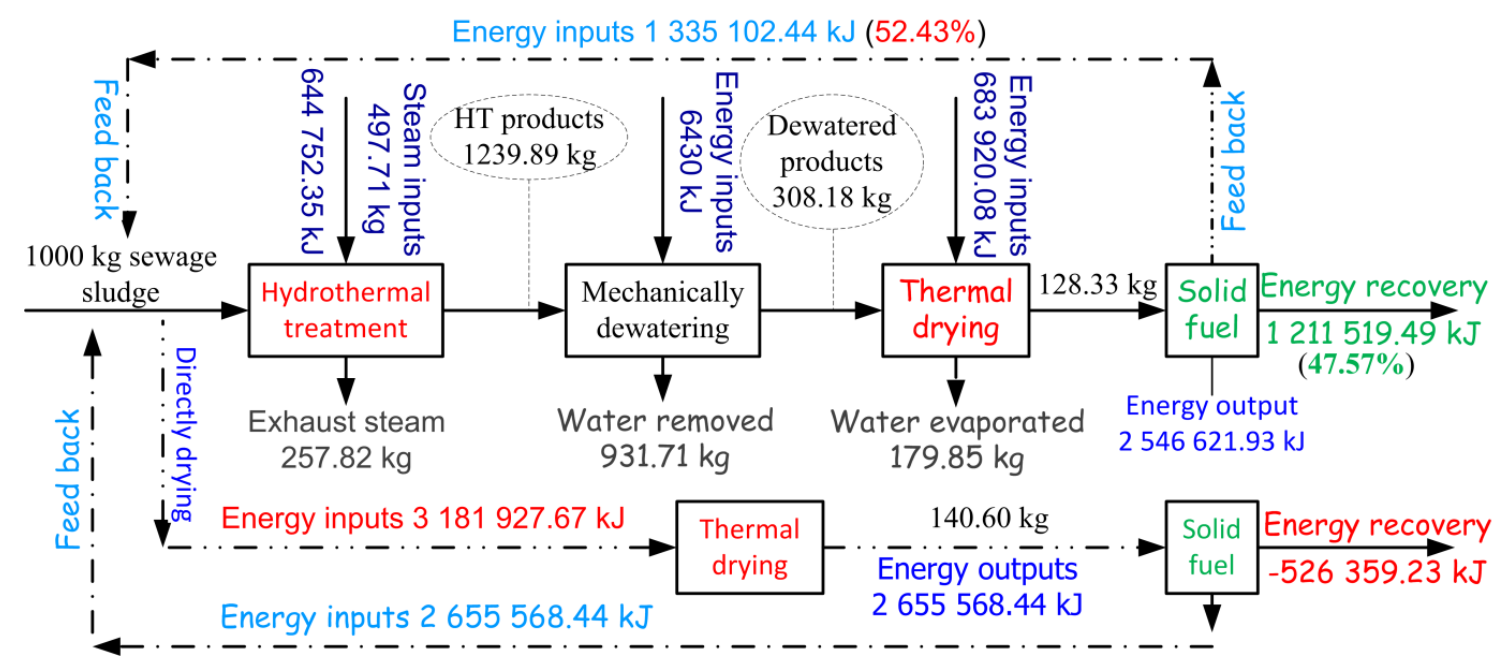

Fig.5 (color on the Web (free of charge) and in black-and-white 